\title{
Challenges to Overcome Barriers against Successful Implementation of Rapid Response Systems
}

\author{
Eun Young Choi \\ Division of Pulmonology and Critical Care Medicine, Department of Internal Medicine, Yeungnam University College of Medicine, Daegu, Korea
}

In Korea, patient's safety is becoming an important issue. Patients who experience adverse events during their hospital stay, including cardiopulmonary arrest, unplanned intensive care unit admissions, and unexpected death, show clear signs of deterioration in the hours preceding the event $[1,2]$. About one-half of the serious adverse events are deemed to be preventable [3]. Patients often show some signs of physiological deterioration for several hours (median 6 hours) before cardiac arrest $[4,5]$. Early recognition and response to patient deterioration have reduced the potential impact of such adverse events [6,7].

Health professionals need to recognize and respond to early signs of patient deterioration and activate rapid response systems (RRSs) to provide rapid medical intervention. RRSs have been developed for timely identification and treatment of patients in general wards at risk for clinical deterioration [8]. RRSs have been implemented widely around the world over the past two decades and have been shown to effectively reduce in-hospital cardiopulmonary arrests.

Recently, RRSs have been implemented in some large hospital in Korea; their effectiveness was uncertain. This is the first multicenter survey on the impacts of RRSs. Implementation of RRSs showed a statistically significant reduction of the cardiopulmonary arrest rates (odds ratio [OR], 0.731; 95\% confidence interval [CI], 0.577 to $0.927 ; \mathrm{P}=0.009$ ), whereas cardiopulmonary resuscitation rates of 2013 and 2015 did not change in hospitals without RRS (OR, 0.988; 95\% CI, 0.868 to $1.124 ; \mathrm{P}=0.854)$.

RRS can diminish in-hospital cardiopulmonary arrests and improve patient safety through earlier identification and treatment attempts. Despite these benefits, there have been barriers against successful implementation of RRS. First, there is a lack of specialists and physicians for RRS implementation. Also, the optimal composition of the RRS team is uncertain. Two previous single-center reports did not show the benefits of intensivist-led teams compared with registrar or resident-led teams $[9,10]$.

\section{Eun Young Choi \\ Division of Pulmonology and Critical Care Medicine, Department of Internal Medicine, Yeungnam University College of Medicine, 170 Hyeonchung-ro, Nam- gu, Daegu 42415, Korea Tel: $+82-53-623-3828$ \\ Fax: +82-53-623-8201 \\ E-mail: letact@hanmail.net \\ ORCID \\ Eun Young Choi http://orcid.org/0000-0003-2974-5447}

*No potential conflict of interest relevant to this article was reported. 
The majority of RRS interventions did not require the presence of a physician (fluids, oxygen, and diuretics). Maharaj et al. [11] reported that RRSs were associated with a reduction in hospital mortality and cardiopulmonary arrest. However, meta-regression did not identify the presence of a physician in the RRS to be significantly associated with a mortality reduction. We need to develop proper RRS model that is applicable to our country. Second, there is a lack of financial support for RRS. Moreover, the absence of government policy about RRS is an important issue to be addressed. In particular, the government needs to make efforts not to increase regional medical gaps. In the future, we need time to share experiences with RSS systems between hospitals.

\section{References}

1. Hillman KM, Bristow PJ, Chey T, Daffurn K, Jacques T, Norman SL, et al. Duration of life-threatening antecedents prior to intensive care admission. Intensive Care Med 2002;28:1629-34.

2. Kause J, Smith G, Prytherch D, Parr M, Flabouris A, Hillman K, et al. A comparison of antecedents to cardiac arrests, deaths and emergency intensive care admissions in Australia and New Zealand, and the United Kingdom: the ACADEMIA study. Resuscitation 2004;62:275-82.

3. Neale G, Woloshynowych M, Vincent C. Exploring the causes of adverse events in NHS hospital practice. J R Soc Med 2001;94:322-30.

4. Buist MD, Jarmolowski E, Burton PR, Bernard SA,
Waxman BP, Anderson J. Recognising clinical instability in hospital patients before cardiac arrest or unplanned admission to intensive care: a pilot study in a tertiary-care hospital. Med J Aust 1999;171:22-5.

5. Franklin C, Mathew J. Developing strategies to prevent inhospital cardiac arrest: analyzing responses of physicians and nurses in the hours before the event. Crit Care Med 1994;22:244-7.

6. Chen J, Ou L, Hillman K, Flabouris A, Bellomo R, Hollis SJ, et al. The impact of implementing a rapid response system: a comparison of cardiopulmonary arrests and mortality among four teaching hospitals in Australia. Resuscitation 2014;85:1275-81.

7. Chen J, Ou L, Hillman KM, Flabouris A, Bellomo R, Hollis SJ, et al. Cardiopulmonary arrest and mortality trends, and their association with rapid response system expansion. Med J Aust 2014;201:167-70.

8. Jones DA, DeVita MA, Bellomo R. Rapid-response teams. N Engl J Med 2011;365:139-46.

9. Morris DS, Schweickert W, Holena D, Handzel R, Sims C, Pascual JL, et al. Differences in outcomes between ICU attending and senior resident physician led medical emergency team responses. Resuscitation 2012;83:1434-7.

10. Karvellas CJ, de Souza IA, Gibney RT, Bagshaw $\mathrm{SM}$. Association between implementation of an intensivist-led medical emergency team and mortality. BMJ Qual Saf 2012;21:152-9.

11. Maharaj R, Raffaele I, Wendon J. Rapid response systems: a systematic review and meta-analysis. Crit Care 2015;19:254. 